\title{
Theoretical Nexus between Social Values, Deviance and Security in Nigeria
}

\author{
Dr. Ogaga Ayemo Obaro \\ Department of Sociology and Anthropology \\ University of Benin, Benin City, Nigeria. \\ E-mail:ogagaobaro@yahoo.com
}

Doi:10.5901/ajis.2013.v2n3p391

\begin{abstract}
The aim of the article is to provide a theoretical nexus between social values, deviance and security in Nigeria. In Nigeria today, society at large is threatened by deviance, crime, conflict and violence which are violations of societal values and norms of security and welfare of the citizenry. People now show an increased interest in personal well-being and a decreased interest in the welfare of others. Citizens are not safe and secure on the streets, in their homes and offices. The paper posits that there should be a renewed awareness regarding social values and norms of security and welfare of the citizenry as taking precedence over all other subjects. Societal values and norms, and security and welfare of all citizens must be articulated. The paper challenges the collective lethargy of the state and the citizenry about societal values, norms and security, and effective measures to protect the rights to living and well being of all members of society, and so maintain a safe and secure environment for all citizens.
\end{abstract}

Keywords: Social, Values, Deviance, Insecurity, Nigeria

\section{Introduction}

The security and welfare of the people shall be the primary purpose of Government (Federal Republic of Nigeria, 1999). But in Nigeria today the state and citizens are subjected to violations of core values and norms, and exposed to danger even by the very governments that are maintained with their taxes. The problem of security is more disturbing because government functions have been personalized by the ruling class, and national interest and security of the nation have been equated with interest of the privileged class and elites. It is common knowledge that the security organizations have distorted views of their constitutional roles, their commitment to the people of this nation, and their tendencies to be part and parcel of different regimes' illegalities, oppression, exploitation and extortion of the common citizens (Imobighe, 2003).

Deviance or crime is concerned with the process whereby values, beliefs, norms, actions or conditions come to be viewed as deviant or criminal by others. Deviance and crime can be observed by the negative, stigmatizing social reaction of others towards these violations. Criminality, corruption, conflict, cultism, violence and terrorism, and all illegalities, oppression, exploitation and extortion of the common man, can be deviant behaviours. The issue of power cannot be divorced from a definition of deviance or crime because some groups in society can deviantize or criminalize the actions of another group by using their influence on legislations (Goode, 2004).

\section{Social Values}

Societies and Cultures have values that are largely shared by their members. The values of a society can often be identified by noting which people receive honour or respect. Values can be defined as broad preferences concerning appropriate courses of action or outcomes (Santrock, 2007). "Equal rights for all", "Excellence deserves admiration", and "People should be treated with respect and dignity" are representative of values. Values tend to influence attitudes and behavior. For example, if we value equal rights and justice for all and act in ways that treat some citizens much better than others, we may form the attitude that the society is an unfair place to live in. It is likely that if the society has a more egalitarian policy, our attitudes and behaviors would be more positive.

Over the last three decades, people have shown an increased interest in personal well-being and a decreased interest in the welfare of others (Santrock, 2007). Values seem to have changed, affecting the beliefs, and attitudes of people. Adopting unfair means in any walk of life for any reason whatsoever was regarded as evil in the past. People tried 
to keep themselves away from all sorts of malpractices and misdeeds. "Honesty is the best policy"; was the motto of the people in general. The deviants, criminal or corrupts were in great disrepute in society. They were hated by all and sundry. But today those social values are interpreted the other way round. Now the criminals are honored as heroes of society. The people are afraid to speak against their evil deeds. The bases of the present social values are the materialistic attitude of the people in general. With a few exceptions, people now run after name, fame and fortune without giving any thought to right or wrong, good or evil, moral or immoral. The effects of social values in the present age are deplorable. The noble qualities are now in exile. Honest people are now pushed to the wall. The wrong doers are held in high esteem because of their wealth, power and position in society.

\section{Deviance}

Sociologists have characterized deviance as any thought, feeling or action that members of a social group judge to be a violation of their values or rules (Douglas and Waksler 1982); violation of the norms of a society or group (Goode, 2004); conduct that violates definitions of appropriate and inappropriate conduct shared by the members of a social system (Jensen, 2007); the departure of certain types of behavior from the norms of a particular society at a particular time (Dinitz and Clark 1969); and violation of certain types of group norms where behavior is in a disapproved direction and of sufficient degree to exceed the tolerance limit of the community (Clinard, 1968). A normative definition views crime as deviant behavior that violates prevailing norms prescribing how humans ought to behave normally.

\section{Security}

The expected dividends of democratic governance include political and social stability, enriched and sustained quality of life, including security of life and property for all the citizens. But in Nigeria today, neither the individual nor the state appears, any longer, to be at ease, as far as security is concerned. Security has to do with freedom from danger or threats to nation's ability to protect and develop itself, promote its cherished values and legitimate interest, and enhance the well-being of its people; security has to do with 'freedom from danger, fear, anxiety or uncertainty; it is a condition of being protected from, or not being exposed to danger (Imobighe, 2003). Unfortunately, it is the individual, rather than the state, that suffers more and bears the greater burden of the consequences and agonising climate of insecurity that overhangs the entire nation.

The security threats to Nigeria include the assemblage of the ills that bedevil the nation's socio-economic and political life among which are corruption, violence, ethno-religious conflicts, ethnic militias and armed gangs, economic crisis, subversion, sabotage and smuggling, armed robbery, kidnapping, arson and killing for religious, ethnic, political and economic reasons. Currently of concern to all Nigerians is the escalating wave of insecurity and criminal activities, that the police and other law enforcement agencies have demonstrated an unacceptable and embarrassing lack of operational capacity to arrest and contain. The state has apparently ceased to be in full control and command of the national security situation, especially as it affects the individual common citizens. The security regime has been hijacked, undermined and compromised by criminals who operate confidently with reckless abandon and little regard for decency and respect for human life.

\section{Theoretical Bases}

\subsection{Structural-Functionalism}

Durkheim's basic insight claimed that deviance (including crime and insecurity) was in fact a normal and necessary part of social organization (Macionis and Gerber, 2010). When he studied deviance he stated four important functions of deviance. Deviance affirms cultural values and norms. Any definition of virtue rests on an opposing idea of vice: there can be no good without evil and no justice without deviance (Macionis and Gerber, 2011). Deviance defines moral boundaries, people learn right from wrong by defining people as deviant. A serious form of deviance forces people to come together and react in the same way against it. Deviance pushes society's moral boundaries which, in turn leads to social change.

Societal integration is the attachment of members of society to groups and institutions, while social regulation is the adherence to the norms and values of the society. Those who are very integrated fall under the category of "altruism" and those who are not very integrated fall under "egoism." Similarly, those who are very regulated fall under "fatalism" and 
those who are very unregulated fall under "anomie". Durkheim's strain theory attributes social deviance to extremes of the dimensions of the social bond. Likewise, individuals may commit deviance or crimes for the good of an individual's group, for the self due to or justified by lack of ties, or because the societal norms that place the individual in check no longer have power due to society's corruption of the values and norms, and associated sanctions and institutions.

Merton discusses deviance in terms of goals (or values) and means (or norms) as part of his strain and anomie theory. Where Durkheim states that anomie is the confounding of social norms, Merton goes further and states that anomie is the state in which social goals (values) and the legitimate means (norms) to achieve them do not correspond. He postulates that an individual's response to societal expectations (values) and the means (norms) by which the individual pursues those goals (values) is useful in understanding deviance and criminality. Specifically, he views collective action as motivated by strain, stress, or frustration in a body of individuals that arises from a disconnection between the society's goals (values) and the popularly used means (norms) to achieve those goals (values). Often, nonroutine collective behavior such as rioting, rebellion, etc. is said to map onto economic explanations and causes by way of strain. These two dimensions determine the adaptation to society according to the cultural goals (values), which are the society's perceptions about the ideal life, and to the institutionalized means (norms), which are the legitimate means (values) through which an individual may aspire to the cultural goals or values (Macionis and Gerber, 2010).

Merton describes five types of attitude and behaviour in terms of the acceptance or rejection of social goals (values) and the institutionalized means (norms) of achieving them: Innovation is a response due to the strain generated by our culture's emphasis on wealth and the lack of opportunities to get rich, which causes people to be "innovators" by engaging in crime. Innovators accept society's goals (values), but reject socially acceptable means (norms) of achieving them (e.g.: monetary success is gained through crime). Merton claims that innovators are mostly those who have been socialised with similar world views to conformists, but who have been denied the opportunities they need to be able to legitimately achieve society's goals (values) (Macionis and Gerber, 2010). Conformity accepts society's goals (values) and the socially acceptable means (norms) of achieving them (e.g. monetary success is gained through hard work). Merton claims that conformists are mostly middle class people in middle class jobs who have been able to access the opportunities in society such as a better education to achieve monetary success through hard work (Macionis and Gerber, 2010). Ritualism refers to the inability to reach a cultural goal (value) thus embracing the rules to the point where they lose sight of their larger goals (values) in order to feel respectable; Ritualists reject society's goals (values), but accept society's institutionalized means (norms). Ritualists are most commonly found in dead-end, repetitive jobs, where they are unable to achieve society's goals (values) but still adhere to society's means (norms) of achievement (Macionis and Gerber, 2010). Retreatism is a response that shows the inability of a person to reject both the cultural goals (values) and means (norms) letting the person "drop out". Retreatists reject the society's goals (values) and the legitimate means (norms) to achieve them; they commit acts of deviance to achieve things that do not always go along with society's values (Macionis and Gerber, 2010). Rebellion is the rejection of society's goals (values) and means (norms) to achieve them, and instead create new goals (values) and means (norms) to replace those of society, creating not only new goals (values) to achieve but also new means (norms) to achieve these goals (values) that other rebels will find acceptable (Macionis and Gerber, 2010).

\subsection{Symbolic Interactionism}

People gain their images and opinions about the nature and extent of crime and insecurity through the media. Much of our vicarious experiences with the crime of the poor is filtered through the mass media. Newspaper and Television news, much of which teeters on the edge between fact and fiction, is highly sensational, selective to time and place, and focuses primarily on the bad. Such depictions are not based on reality, but rather on the wants of a presumed audience. All forms of news accounts, though they are mandated to be based on an objective reality, are largely based on consumer demand. What we are left with, then, is a gulf between reality and perception. The reality is that the poor are mostly disenfranchised from the democratic process at all levels of governance. They are disadvantaged in the labour market and have few services available to them unlike the rich world. When they do break the law, they victimize other poor who are like them (Charon, 2007).

In his differential association theory, Edwin Sutherland posites that criminals learn criminal and deviant behaviors and that deviance is not inherently a part of a particular individual's nature. When an individual's significant others engage in deviant and/or criminal behavior, criminal behavior will be learned as a result of this exposure (Botterweck, et. al., 2011). Also, he argues that criminal behavior is learned in the same way that all other behaviors are learned, meaning that the acquisition of criminal knowledge is not unique compared to the learning of other behaviors. 
Sutherland outlines some very basic points in his theory, such as the idea that the learning comes from the interactions between individuals and groups, using communication of symbols and ideas. When the symbols and ideas about deviation are much more favorable than unfavorable, the individual tends to take a favorable view upon deviance and will resort to more of these behaviors. Criminal behavior (motivations and technical knowledge), as with any other sort of behavior, is learned. Some basic assumptions include: learning in interaction using communication within intimate personal groups; techniques, motives, drives, rationalizations, and attitudes are all learned; excess of definitions favorable to deviation; legitimate and illegitimate behaviors both express the same general needs and essential values. One example of this would be gang activity in inner city communities. Sutherland would feel that because a certain individual's primary influential peers are in a gang environment, it is through interaction with them that one may become involved in crime (Botterweck, et. al., 2011).

Gresham Sykes and David Matza's neutralization theory explains how deviants and criminals justify their behaviors by providing alternative definitions of their actions and by providing explanations, to themselves and others, for the lack of guilt for actions in particular situations. There are five major types of neutralization. Denial of responsibility: the deviant believes s/he was helplessly propelled into the deviance, and that under the same circumstances, any other person would resort to similar actions. Denial of injury: the deviant believes that the action caused no harm to other individuals or to the society, and thus the deviance is not morally wrong. Denial of the victim: the deviant believes that individuals on the receiving end of the deviance were deserving of the results due to the victim's lack of virtue or morals. Condemnation of the condemners: the deviant believes enforcement figures have the tendency to be equally deviant or otherwise corrupt, and as a result, are hypocrites to stand against. Appeal to higher loyalties: the deviant believes that there are loyalties and values that go beyond the confines of the law- morality, friendships, income, or traditions may be more important to the deviant than legal boundaries (Sykes and Matza, 1957).

Tannenbaum and Becker created and developed the labelling theory, which is a core facet of symbolic interactionism, and often referred to as Tannenbaum's "dramatization of evil." Becker believed that "social groups create deviance by making the rules whose infraction constitutes deviance." Labelling is a process of social reaction by the "social audience,"(stereotyping) the people in society exposed to, judging and accordingly defining (labeling) someone's behavior as deviant or otherwise. It has been characterized as the "invention, selection, manipulation of beliefs which define conduct in a negative way and the selection of people into these categories" (Jensen, 2001).

Labeling theory, consequently, suggests that deviance is caused by the deviant's being labeled as morally inferior, the deviant's internalizing the label and finally the deviant's acting according to that specific label: in other words, you label the "deviant" and they act accordingly. As time goes by, the "deviant" takes on traits that constitute deviance by committing such deviations as conform to the label. So as the audience has the power to not label deviants, they have the power to stop the deviance before it ever occurs by not labeling them. Individual and societal preoccupation with the label, in other words, leads the deviant individual to follow a self-fulfilling prophecy of abidance to the ascribed label (Macionis and Gerber, 2010).

This theory while very much symbolically interactionist, also has elements of conflict theory, as the dominant group has the power to decide what is deviant and acceptable, and enjoys the power behind the labeling process. An example of this is a prison system that labels people convicted of theft, and because of this they start to view themselves as by definition, thieves, incapable of changing. "From this point of view," as Becker (1963) has written, deviance is not a quality of the act the person commits, but rather a consequence of the application by others of rules and sanctions to an "offender". The deviant is one to whom the label has successfully been applied; deviant behavior is behavior that people so label. In other words, Behavior only becomes deviant or criminal if defined and referred to as such by specific people in a specific situation (Goode, 2004). It is important to note the salient fact that society is not always correct in its labeling, often falsely identifying and misrepresenting people as deviants, or attributing to them characteristics which they do not have. In legal terms, people are often wrongly accused, yet many of them must live with the ensuant stigma (or conviction) for the rest of their lives. On a similar note, society often employs double standards, with some sectors of society enjoying favouritism. Certain behaviors in one group are seen to be perfectly acceptable, or can be easily overlooked, but in another are seen, by the same audience, as abominable.

Edwin Lemert developed the idea of primary and secondary deviation as a way to explain the process of labeling. Primary deviance is any general deviance before the deviant is labeled as such. Secondary deviance is any action that takes place after primary deviance as a reaction to the institutional identification of the person as a deviant (Macionis and Gerber, 2010). When an actor commits a crime (primary deviance), however mild, the institution will bring social penalties down on the actor. However, punishment does not necessarily stop crime, so the actor might commit the same primary deviance again, bringing even harsher reactions from the institutions. At this point, the actor will start to resent the 
institution, while the institution brings harsher repression. Eventually, the whole community will stigmatize the actor as a deviant and the actor will not be able to tolerate this, but will ultimately accept his or her role as a criminal, and will commit criminal acts that fit the role of a criminal. Primary and secondary deviation is what causes people to become harder criminals.

\subsection{Control theory}

Control theory advances the proposition that weak bonds between the individual and society free people to deviate. By contrast, strong bonds discourage deviance, crime and insecurity. This theory asks why people refrain from deviant or criminal behavior, instead of why people commit deviant or criminal behavior (Hirschi 2002). The control theory developes when norms emerge to deter deviant behavior. Without this "control", deviant behavior would happen more often. People will conform to a group when they believe they have more to gain from conformity than by deviance. If a strong bond is achieved there will be less chance of deviance than if a weak bond has occurred. Hirschi argues that people follow the norms because they have a bond with society. The bond consists of four positively correlated factors: opportunity, attachment, belief, and involvement (Macionis and Gerber, 2010). When any of these bonds are weakened or broken one is more likely to act in defiance. Gottfredson and Hirschi (1990) founded their Self-Control Theory which states that acts of force and fraud are undertaken in the pursuit of self-interest and self-control. A deviant act is based on criminals own self-control of themselves.

More contemporary control theorists take the theory into a new light suggesting labor market experiences not only affect the attitudes and the "stakes" of individual workers, but can also affect the development of their children's views toward conformity and cause involvement in delinquency (Ramdhan, 2011; Wadsworth, 2000). This is an ongoing study as he has found a significant relationship between parental labor market involvement and children's delinquency, but has not empirically demonstrated the mediating role of parents' or children's attitude (Ramdhan, 2011). The research tried to show a correlation between labor market stratification and individual behavior. In a study conducted by Tim Wadsworth, the relationship between parent's employment and children's delinquency was shown empirically for the first time. The findings from this study supported the idea that the relationship between socioeconomic status and delinquency might be better understood if the quality of employment and its role as an informal social control is closely examined (Wadsworth, 2000).

\subsection{Conflict theory}

Conflict theory states that society or an organization functions so that each individual participant and its groups struggle to maximize their benefits, which inevitably contributes to social change such as political changes and revolutions. Conflict theory is based upon the view that the fundamental causes of crime are the social and economic forces operating within society. This theory also states that the powerful define deviance, crime and security. This raises the question: for whom is this theory functional? In this theory, laws are instruments of oppression: tough on the powerless and not-or-less tough on the powerful (MacNamara and Karmen, 1983).

\section{Conclusion}

In Nigeria today, social values of honesty, sincerity, truthfulness and fellow feeling have taken the "back burner", affecting the beliefs, attitudes and behaviour of people; people now show an increased interest in personal well-being and a decreased interest in the welfare of others. Deviant acts have become assertions of individuality and identity, and thus as rebellions against group values and norms of the dominant culture and in favour of a sub-culture. But deviance also affirms cultural values and norms; clarifies moral boundaries; promotes social unity by creating us-and-them dichotomy; encourages social change; and provides jobs to control deviance, criminality and insecurity (Hastings and O'Neil, 2009). Ultimately, social values are the root of all virtues that pave the way for harmony and the key to the development of a society. Therefore, societal values and norms of security and welfare of all citizens must be articulated and practiced in order to maintain a safe and secure environment for all citizens.

\section{References}

Botterweck, Michael C. et. al., Eds. (2011). Everyday Sociology. Elmhurst, Il.: Starpoint Press. Becker, Howard (1963). Outsiders: Studies in Sociology of Deviance. New York: Free Press. 
Charon J.M. (2007). Symbolic Interactionism: An Introduction, An Interpretation, Integration. Upper Saddle River, NJ: Perason Prentice Hall.

Clinard, M. B. and Meier, R. F. (1995), Sociology of deviant behavior (9th Edition). New York:

Harcourt Brace College Publishers.

Dinitz, S., Dynes, R. R. and Clarke, A. C. (1975). Deviance: studies in definition, management, and treatment. New York: Oxford University Press.

Douglas, J. D and Waksler, F. C. (1982). The sociology of deviance: an introduction. Boston: Little Brown.

Goode, E. (2004). Deviant Behavior (7th edn.). Upper Saddle River, NJ: Pearson.

Gottfredson, M. and Hirschi, T. (1990). A General Theory of Deviance. California: Stanford University Press.

Hastings, S. E. and O'Neil, T. A. (2009). "Predicting workplace deviance using broad versus narrow personality variables". Journal of Personality \& Individual Differences, 47:289-293.

Hirschi, T. (2002). Causes of delinquency. New Brunswick, N.J.: Transaction Publishers

Imobighe,T. (2003). Nigeria Defence and National Security Linkages: A Framework of Analysis. Ibadan: Heinemann Books.

Jensen, G. F. (2007). The path of the devil: early modern witch hunts. New Jersey: Rowman \& Littlefield.

Macionis, J. and Gerber, L. (2010). Sociology: Emile Durkheim's Basic Insight (7th edition). Toronto, Ontario: Pearson Canada Inc.

MacNamara, D. E. J. and Karmen, A. (1983). Deviants: Victims or Victimizers? Beverly Hills, California: Sage.

Ramdhan, S. (2011). A study of the extent and forms of school violence and delinquency: The dynamics of race, gender, social class, limited opportunity for employment, poverty and family background among the high risk Secondary School in Trinidad. GRIN Verlag. p. 8. Available: http://www.grin.com/en/e-book/175784/a-study-of-the-extent-and-forms-of-school-violence-anddelinquency (November 24, 2012).

Santrock, J.W. (2007). A Topical Approach to Life-Span Development. NY: McGraw-Hill

Stark, R. (2007). Sociology: Biological Theories of Deviance (10th Edition). Belmont, CA: Thompson Wadsworth.

Sykes, G. and Matza, D. (1957). "Techniques of Neutralization: A Theory of Delinquency". American Sociological Review, 22,664 - 70.

Wadsworth, T. (1999-2000). Labor Markets, Delinquecy, and Social Control Theory: An Empirical Assessment of the Mediating Process. Available: en.wikipedia.org/wiki/deviance_(sociology) (August 26, 2013). 